\title{
Follicular atresia in relation to oocyte morphology in non-pregnant and pregnant women
}

\author{
L. Westergaard \\ Department of Obstetrics and Gynecology, Afsnit 537, Hvidovre Hospital, Kettegårds Allé 30, \\ 2650 Hvidovre, Denmark
}

\begin{abstract}
Summary. Antral follicles from normally menstruating women and women in the third trimester of pregnancy were classified as healthy or atretic by flow cytometric DNA measurements on aspirated granulosa cells and by the concentration of steroids in the follicular fluid. The oocytes contained in these follicles were characterized as healthy or degenerating by their morphology at the light microscopic level. In $98 \%$ of the cases (61/62) morphologically healthy or degenerating oocytes were found in follicles which were classified as healthy or atretic respectively. In the normally menstruating women degenerative changes in the oocyte and the remainder of the follicle appeared to occur in synchrony. In pregnant women asynchrony was noted between the oocyte and the remainder of the follicle as follicular atresia progressed. The present study demonstrated the usefulness of flow cytometric DNA measurement in characterizing antral follicles of all sizes as healthy or more or less atretic.
\end{abstract}

\section{Introduction}

Although a large majority ( $>99 \%$ ) of antral follicles in the human ovary become atretic at some stage of their development, little is known about the cause of follicular atresia (Byskov, 1978). It is also uncertain whether the process of atresia is initiated in the oocyte followed by degeneration of the granulosa cells or vice versa, or whether it occurs simultaneously in the two structures (Block, 1951; Breitenecker, Friedrich, Golob \& Pavelka, 1975; Peluso, Breitenecker \& Hafez, 1979; McNatty, Moore Smith, Makris, Osathanondh \& Ryan, 1979).

Antral follicles with diameters $>5 \mathrm{~mm}$ may be classified as preovulatory, non-ovulatory healthy or atretic by the concentrations of progesterone, androstenedione, testosterone, and oestradiol in the follicular fluid (McNatty et al., 1979; Bomsel-Helmreich et al., 1979). However, small antral follicles with diameters $₹ 5 \mathrm{~mm}$ are not distinguishable as healthy or atretic by these hormonal criteria (McNatty et al., 1983). Flow cytometric DNA analysis on the granulosa cells contained in the follicular fluid aspirate offers an alternative method to characterize non-ovulatory follicles of various sizes as healthy or atretic (Westergaard, McNatty, Christensen, Larsen \& Byskov, 1982).

In the present study follicular fluid samples and oocytes were aspirated from the ovaries of women with normal menstrual cycles or in the third trimester of pregnancy. The aim of the study was to correlate the flow cytometric and hormonal findings in follicular fluid aspirates with the morphological appearance of the oocytes in these two groups of women.

\section{Materials and Methods}

Subjects

Oocytes and follicular fluid were obtained by aspiration of antral follicles from 45 healthy women (19-40 years old) undergoing laparotomy. Thirty of these women had normal menstrual $1: 18: 01 \mathrm{AM}$ 
cycles (Group A), and 15 women were in the third trimester of pregnancy (Group B). The indications for surgery were legal sterilization for Group A and elective Caesarean section for Group B. The women were informed about the aim of the study and the procedure before operation, and all agreed to participate.

\section{Methods}

The stage of the menstrual cycle was assessed from the day of the last menstrual period, endometrial histology and measurement of pituitary and steroid hormones in peripheral blood obtained on the day of operation.

Recovery of antral fluid, granulosa cells and oocytes. During laparotomy and with the ovaries in situ the diameters of visible antral follicles were measured, and their contents aspirated using a 25gauge needle (Butterfly-25 Short: Abbott Laboratories, Trørød, Denmark). Blood-contaminated aspirates were discarded since admixture of leucocytes would interfere with the DNA analysis. The clear aspirates were immediately transported on ice to the laboratory and examined under a stereomicroscope $(\times 50)$ for the presence of an oocyte. When identified the oocyte was removed and fixed in $3 \%$ glutaraldehyde for $30 \mathrm{~min}$. The remaining follicular fluid was centrifuged at $200 \mathrm{~g}$ for $5 \mathrm{~min}$. The supernatants and sediments (i.e. granulosa cell pellets) were stored as previously described (Westergaard et al., 1982).

Aspirates were obtained from 230 follicles and the oocyte was located in $70(30 \%)$ of these. During fixation and embedding procedures 8 of the oocytes were lost, leaving 62 oocytes aspirated from 62 follicles (Group A, 36; Group B, 26) available for this study. Hormonal and flow cytometric findings for 18 of these follicles have appeared as part of a previously published study (Westergaard et al., 1982).

Preparation and classification of the oocytes. The oocytes were postfixed in $1 \%$ osmium tetroxide, dehydrated, embedded in Epon 812, serially sectioned at $1 \mu \mathrm{m}$ and stained with toluidine blue (Zamboni, Thompson \& Smith, 1972). The oocytes were classified according to the morphological characteristics of the cumulus cells, the zona pellucida, the ooplasm and the oocyte nucleus, and put into one of the following 4 categories (Steptoe \& Edwards, 1970; Zamboni et al., 1972; Shea, Baker \& LaTour, 1975; Peluso et al., 1979). (i) Preovulatory oocytes were characterized by an 'activated' cumulus (Steptoe \& Edwards, 1970), absent nucleus, and presence of the first polar body in a small perivitelline space. (ii) Non-ovulatory healthy oocytes had a zona pellucida which was even in thickness and surrounded by 3 or more layers of tightly packed cumulus cells with no or few pycnotic nuclei and occasional mitotic figures. The vitelline membrane was adjacent to the inner aspect of the zona pellucida, the ooplasm was homogeneous, and a vesicular nucleus with a smooth nuclear membrane was located centrally or slightly off centre. (iii) Early atretic oocytes, in which the zona pellucida was surrounded by 1-3 layers of cumulus cells amongst which some pycnotic nuclei were seen, contained a moderately enlarged perivitelline space with the vitellus slightly shrunken. The ooplasm showed a moderate degree of organelle clumping and vacuolization, the nucleus was usually located peripherally and the nuclear membrane was undulated or irregular. (iv) Late atretic oocytes, which were totally or partly deprived of cumulus and corona cells (when they were present many pycnotic nuclei were seen), showed inhomogeneity of the zona pellucida which had variable thickness and pronounced shrinkage of the vitellus leaving a large perivitelline space. The ooplasm was greatly vacuolated and deeply staining organelle clumps were abundant. The nucleus was often not seen but, if present, usually showed fragmentation.

Flow cytometric DNA analysis of aspirated granulosa cells. The granulosa-cell pellets of the centrifuged follicular aspirates were subjected to DNA analysis by flow cytometry as reported previously (Westergaard et al., 1982). By analysis of the resultant DNA histograms the percentage of cells in the $\mathrm{S}$ phase of the mitotic cycle (the $\mathrm{S}$ fraction) was calculated.

Steroid hormone assays. Progesterone, androstenedione, testosterone and oestradiol in the fluid of individual follicles were measured by radioimmunoassay (Westergaard et al., 1982). All assays were performed in triplicate, and the intra- and inter-assay coefficients of variations were $<15 \%$. 
Classification of follicles. The follicles were assigned to one of the following categories (McNatty et al., 1979; Westergaard et al., 1982). Preovulatory follicles were the largest follicles aspirated in the late follicular phase of the cycle, with high follicular fluid progesterone and oestradiol. (The $S$ fraction cannot be used to characterize preovulatory follicles.) Non-ovulatory healthy follicles were those with an $\mathrm{S}$ fraction of $>16 \%$, a diameter $>5 \mathrm{~mm},>200 \mathrm{ng}$ oestradiol $/ \mathrm{ml}$ follicular fluid and an androstenedione : oestradiol ratio of $<4$. Atretic follicles were those with an $\mathrm{S}$ fraction of $<16 \%$, $<200 \mathrm{ng}$ oestradiol/ml follicular fluid and an androstenedione :oestradiol ratio of $>4$. Follicles with diameters $₹ 5 \mathrm{~mm}$ were classified as healthy or atretic according to the results of flow cytometry alone, since the follicular fluid oestradiol value and the androstenedione :oestradiol ratio are not useful criteria for characterizing small follicles (McNatty et al., 1983).

For the purpose of this study all atretic follicles were subdivided into $+\mathrm{S}$ atretic follicles with $\mathrm{S}$ fractions of $<16 \%$, and $-\mathrm{S}$ atretic follicles in which an $\mathrm{S}$ fraction determination was not possible because the aspirates contained very few granulosa cells (i.e. $<2000$ ) or large amounts of cellular debris.

Statistical methods. Differences in $\mathrm{S}$ fractions and steroid concentrations amongst groups of follicles were tested statistically using the Wilcoxon rank sum test for non-paired data.

\section{Results}

All of 8 oocytes (Group A) from preovulatory follicles were classified as preovulatory, and all 4 oocytes ( 3 from Group A and 1 from Group B) from non-ovulatory healthy follicles were classified as non-ovulatory healthy. Of the 50 oocytes that were classified as atretic (early and late), $49(98 \%)$ were aspirated from follicles classified as atretic. One oocyte (Group A) was classified as early

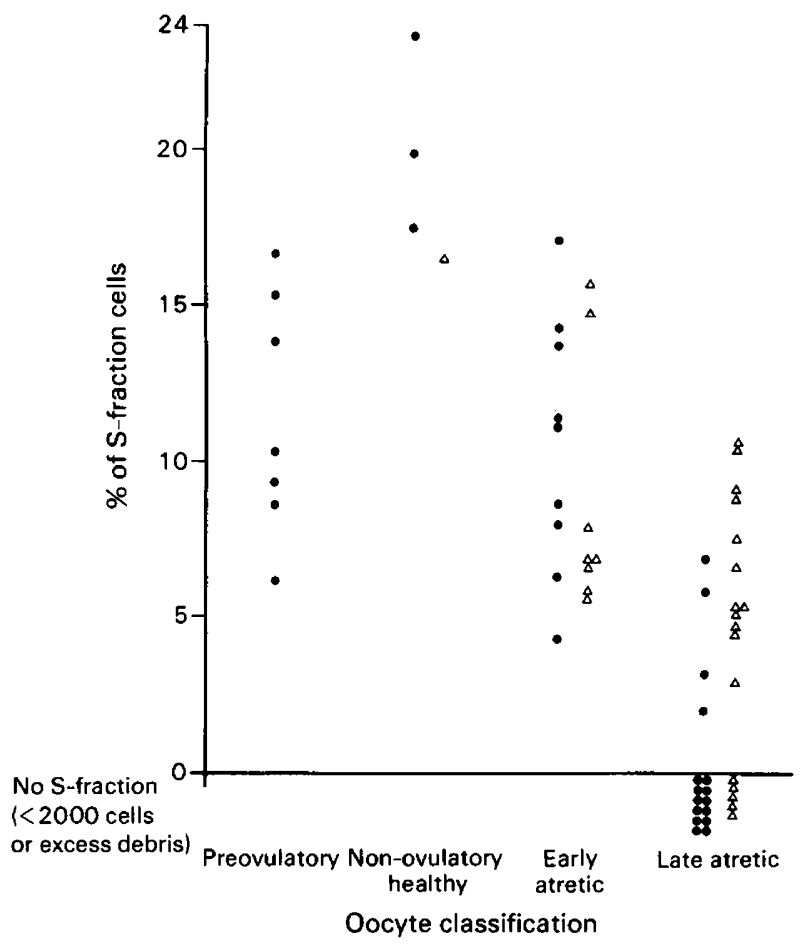

Text-fig. 1. The percentage of granulosa cells in the DNA $S$ phase (=S fraction) in follicular aspirates containing oocytes classified as preovulatory, non-ovulatory healthy, early or late atretic, obtained from women with spontaneous menstruations (, Group $A$ ) or in the third trimester of pregnancy $(\triangle$, Group B). 
atretic, but was aspirated from a non-ovulatory healthy follicle (S fraction, $17 \cdot 1 \%$; follicular fluid oestradiol, $1380 \mathrm{ng} / \mathrm{ml}$ ).

The results of flow cytometry in the individual follicles of Groups A and B in relation to the classification of their oocytes are shown in Text-fig. 1. The mean \pm s.e.m. value of the $S$ fractions (Groups $A$ and $B$ ) in follicles containing non-ovulatory healthy oocytes was $19.4 \pm 1.6 \%(\mathrm{~N}=4)$, which was significantly higher than the $9.7 \pm 1.0 \%(N=17)$ in follicles containing early atretic oocytes $(P<0.01)$. The latter value was significantly higher than the $6.3 \pm 0.6 \%(N=16)$ found in $+\mathrm{S}$ atretic follicles containing late atretic oocytes $(P<0.01)$. Text-figure 1 also demonstrates that all $-\mathrm{S}$ atretic follicles contained late atretic oocytes.

With the exception of an early atretic oocyte that was found in a non-ovulatory healthy follicle, all 16 early atretic oocytes were confined to $+S$ atretic follicles ( 8 in Group $A$, and 8 in Group B). Of the late atretic oocytes in Group $A, 12$ were found in $-S$ atretic follicles and 4 in $+S$ atretic follicles, in contrast to 5 in $-\mathrm{S}$ atretic and 12 in $+\mathrm{S}$ atretic follicles in Group $\mathrm{B}(P<0.025)$.

The diameters of follicles containing non-ovulatory healthy and early and late atretic oocytes in Group A were significantly larger than those of comparable follicles in Group B (Table 1). In Group A, 5 of the follicles had diameters $₹ 5 \mathrm{~mm}$. Of these follicles, which all contained late atretic oocytes, 4 were $-S$ atretic and $1+S$ atretic. In Group B all 26 follicles had diameters $₹ 5 \mathrm{~mm}$. Table 1 also shows $S$ fractions and follicular fluid hormone concentrations for the follicles in Groups A and B. Significant differences between the subgroups within Groups A and B are indicated. The progesterone concentration in Group B follicles containing early and late atretic oocytes was significantly higher than in corresponding follicles in Group $A(P<0.05)$, but none of the other steroids differed significantly between Groups A and B.

Table 1. Mean \pm s.e.m. of diameters, $S$ fractions and follicular fluid hormone concentrations in follicles from menstruating women (Group A) and pregnant women (Group B)

\begin{tabular}{|c|c|c|c|c|c|c|c|}
\hline \multirow{2}{*}{$\begin{array}{l}\text { Oocyte } \\
\text { classification }\end{array}$} & \multirow{2}{*}{$\begin{array}{l}\text { No. of } \\
\text { follicles }\end{array}$} & \multirow{2}{*}{$\begin{array}{l}\text { Diam. } \\
(\mathrm{mm})\end{array}$} & \multirow{2}{*}{$\begin{array}{c}\text { S Fraction - } \\
(\%)\end{array}$} & \multicolumn{4}{|c|}{ Hormone concentration $(\mathrm{ng} / \mathrm{ml})$} \\
\hline & & & & Progesterone & Androstenedione & Testosterone & Oestradiol \\
\hline \multicolumn{8}{|l|}{ Group $A$} \\
\hline Preovulatory & 8 & $19 \pm 3$ & $11 \cdot 5 \pm 1 \cdot 5^{\mathrm{a}}$ & $2628 \pm 946^{a}$ & $621 \pm 115^{\mathrm{a}}$ & $54 \pm 15$ & $885 \pm 227^{a}$ \\
\hline $\begin{array}{l}\text { Non-ovulatory } \\
\text { healthy }\end{array}$ & 3 & $8 \pm 2$ & $20.3 \pm 1.8$ & $242 \pm 100$ & $285 \pm 119$ & $21 \pm 9$ & $604 \pm 234$ \\
\hline Early atretic & 9 & $9 \pm 1$ & $10 \cdot 6 \pm 1 \cdot 4^{\mathrm{a}}$ & $33 \pm 10^{b}$ & $1146 \pm 127^{b}$ & $64 \pm 10$ & $185 \pm 150^{b}$ \\
\hline Late atretic & 16 & $7 \pm 1$ & $4 \cdot 5 \pm 1 \cdot 1^{\mathrm{b}}$ & $59 \pm 20^{b}$ & $841 \pm 111^{b}$ & $37 \pm 10$ & $11 \pm 3^{b}$ \\
\hline \multicolumn{8}{|l|}{ Group B } \\
\hline $\begin{array}{l}\text { Non-ovulatory } \\
\text { healthy }\end{array}$ & 1 & 2 & $16 \cdot 5$ & 51 & 315 & 33 & 36 \\
\hline Early atretic & 8 & $3 \pm 0.3$ & $8.8 \pm 1.4$ & $105 \pm 40$ & $1097 \pm 362$ & $94 \pm 24$ & $27 \pm 7$ \\
\hline Late atretic & 17 & $3 \pm 0.2$ & $6.8 \pm 0.7$ & $74 \pm 11$ & $862 \pm 165$ & $27 \pm 7$ & $35 \pm 6$ \\
\hline
\end{tabular}

Values with different superscripts are significantly different $(P<0 \cdot 05)$.

\section{Discussion}

The present study shows a high degree of correlation between the morphological appearance of aspirated oocytes and the classification of their follicles as healthy or atretic by means of flow cytometric DNA analysis of aspirated granulosa cells and follicular fluid steroid concentration. The results also demonstrate that flow cytometry reflects the different stages of follicular atresia more precisely than follicular fluid steroid concentration which did not reveal whether a follicle contained an oocyte in an early or late stage of degeneration. By contrast, follicles characterized as $-\mathrm{S}$ atretic by flow cytometry invariably contained late degenerating oocytes, and oocytes with 
early degenerative changes were confined to $+S$ atretic follicles. Although some late degenerating oocytes were found in $+S$ atretic follicles, the $S$ fractions in these follicles were significantly lower than in $+\mathbf{S}$ atretic follicles containing oocytes with early degenerative changes. Apparently, a high $\mathrm{S}$ fraction (but $<16 \%$ ) indicates an early stage of atresia, a low $\mathrm{S}$ fraction a later stage of atresia, and follicles characterized as $-S$ atretic are those in the most advanced stage of atresia.

The present findings confirmed that follicles with diameters $₹ 5 \mathrm{~mm}$ could not be classified as healthy or atretic by the concentration or composition of follicular fluid steroids (McNatty et al., 1983), although the classification of these small follicles by flow cytometry was in agreement with the oocyte morphology. Follicles with diameters $>5 \mathrm{~mm}$ were only found in non-pregnant women. With the exception of preovulatory follicles, classification of these follicles as healthy or atretic by flow cytometry was in agreement with classification using follicular fluid hormone concentration, and with the morphological appearance of the oocytes. In non-pregnant women with normal menstrual cycles, growth, maturation and degeneration are processes that generally occur synchronously in the oocyte and the remainder of the follicle, confirming the findings of Block (1951) and McNatty et al. (1979). In pregnant women in the third trimester, however, the present results indicate a certain asynchrony between the oocyte and the remainder of its follicle during the later stages of atresia. In these women the majority of late degenerating oocytes were found in $+S$ atretic follicles. The reason for this asynchrony is obscure. In preantral follicles in the human infant ovary, asynchrony seems to be common since the atretic process often starts in the oocyte (Himmelstein-Braw, Byskov, Peters \& Faber, 1976). Whether this pattern of follicular atresia extends to small antral follicles in the adult ovary is unknown. If so, the above differences between pregnant and non-pregnant women may simply be due to the significantly smaller size of atretic follicles in the pregnant women (all $<5 \mathrm{~mm}$ diameter). In the non-pregnant women only 5 antral follicles had diameters $₹ 5 \mathrm{~mm}$. All of these contained late degenerating oocytes and 4 of them were classified as $-S$ atretic and one as $+S$ atretic. Although the number of observations is limited, this finding indicates that the synchronous degeneration of oocyte and granulosa extends even to small antral follicles in non-pregnant women.

The concentration of progesterone in atretic follicles from pregnant women was significantly higher than in those from non-pregnant women. The importance of this finding in relation to oocyte/follicle atresia is unclear since the influence of follicular fluid steroids on oocyte morphology is poorly understood.

I thank Mrs Ulla Larsen for skilful technical assistance.

\section{References}

Block, E. (1951) Quantitative morphological investigations of the follicular system in women. Acta endocr., Copenh. 8, 33-54.

Bomsel-Helmreich, O., Gougeon, A., Thebault, A., Saltarelli, D., Milgrom, E., Frydman, R. \& Papiernik, E. (1979) Healthy and atretic human follicles in the preovulatory phase: Differences in evolution of follicular morphology and steroid content of follicular fluid. J. clin. Endocr. Metab. 48, 686-694.

Breitenecker, G., Friedrich, F., Golob, E. \& Pavelka, R. (1975) Vergleichende morphologische Untersuchungen der Wand von Bläschenfollikeln des menschlichen Ovars und deren Eizellen. Wien. klin. Wschr. 87, 779-781.

Byskov, A.G. (1978) Follicular atresia. In The Vertebrate Ovary, pp. 523-562. Ed. R. E. Jones. Plenum Press, New York.

Himmelstein-Braw, R., Byskov, A.G., Peters, H. \& Faber,
M. (1976) Follicular atresia in the human infant ovary. J. Reprod. Fert. 46, 55-59.

McNatty, K.P., Moore Smith, D., Makris, A., Osathanondh, R. \& Ryan, K.J. (1979) The microenvironment of the human antral follicle: Interrelationships among the steroid levels in antral fluid, the population of granulosa cells and the status of the oocyte in vivo and in vitro. J. clin. Endocr. Metab. 49, 851860.

McNatty, K.P., Hillier, S.G., van den Boogard, A.M.J., Trimbos-Kemper, T.C.M., Reichert, L.E., Jr \& Van Hall, E.V. (1983) Follicular development during the Juteal phase of the human menstrual cycle. $J$. clin. Endocr. Metab. 56, 1022-1031.

Peluso, J., Breitenecker, G. \& Hafez, E.S.E. (1979) Atresia of ovarian follicles and ova. In Human Ovulation, pp. 177-203. Ed. E. S. E. Hafez. Elsevier/ North-Holland Biomedical Press, Amsterdam. 
Shea, B.F., Baker, R.D. \& LaTour, J.P.A. (1975) Human follicular oocytes and their maturation in vitro. Fert. Steril. 26, 1075-1082.

Steptoe, P.C. \& Edwards, R.G. (1970) Laparoscopic recovery of preovulatory human oocytes after priming of ovaries with gonadotrophins. Lancet i, 683689.

Westergaard, L., McNatty, K.P., Christensen, I.J., Larsen, J.K. \& Byskov, A.G. (1982) Flow cytometric deoxyribonucleic acid analysis of granulosa cells aspirated from human ovarian follicles. A new method to distinguish healthy and atretic ovarian follicles. J. clin. Endocr. Metab. 55, 693-698.

Zamboni, L., Thompson, R.S. \& Smith, D.M. (1972) Fine morphology of human oocyte maturation in vitro. Biol. Reprod. 7, 425-457.

Received 19 July 1984 